\title{
A study on the relationship between acculturation and ethno-cultural identity in Saudi Arabia
}

\author{
Ansa Savad Hamza Salima* \\ ${ }^{a}$ Assistant Professor, Prince Sattam Bin Abdulaziz University, Saudi Arabia \\ C H R O N I C L E \\ Article history: \\ Received: July 10, 2020 \\ Received in revised format: \\ October 182020 \\ Accepted: November 2, 2020 \\ Available online: \\ November 2, 2020 \\ Keywords: \\ Acculturation \\ Ethno-cultural identity \\ Culture \\ Heritage \\ Mainstream
}

\section{Introduction}

The evidence shows a prominent increase across the globe for economic growth and societal well-being, which recommends the significance of Acculturation and Ethno-cultural identity. The local communities have gained substantially significant development and empowerment, thereby leading to economic growth due to the assimilation to a different culture. Even in developing and developed countries, which will facilitate and influence the socio-economic system and bring in inclusive growth. These reasons are fueling the importance of acculturation. The definition given in dictionary is as "acculturation is assimilation to a different culture, typically the dominant one". Acculturation and enculturation are elaborating to impart to the majority of cultural dimensions through lifestyles related to development. This leads to socio-economic development and sustainable growth of a nation associated with all segments of the society. Once a nation starts mixing up with different cultures, that indeed will result in high demand for products and services in the country and turn, which results in the purchase and sale of goods and will lead to a growth in the economy. A possible potential solution to enhance major industries' economic condition and growth is mixing with a different culture. People try to taste other food items while getting a chance to mix up with other traditions. The benefits of integrating with culture are that it could neutralize various social problems such as gender inequality, social exclusion, poverty, etc. and may destroy most economies. Acculturation is considered a relevant social requirement that has the sole power to generate and improve an economy's well-being. The majority of the governments across the globe have confirmed acculturation as a significant element of the country. This research study aims to investigate the process of acculturation and develop different strategies that will help utilize all the resources available in Saudi Arabia effectively. The study aims to examine the extent to which the expatriates in Saudi Arabia are inclined towards acculturation and ethnocultural identity. This project also focuses on finding out significant areas relating to the values to understand the orientation towards culture and heritage.

* Corresponding author. Tel.: +966557560540

E-mail address: ansasalim07@gmail.com (A. Savad Hamza Salim)

(C) 2021 by the authors; licensee Growing Science, Canada doi: $10.5267 /$ j.msl.2020.11.001 
The attitude of Employee's towards the adoption of a different cultures will be reflected in the future of the economy. The major focus on building an acceptable culture in an organization is one of the best socio-economic development strategies. This means an adjustment to relatively varied cultures from the prevalent one. Though many significant factors relating to acculturation have been discussed through several empirical research, there is a dearth of literature about the relationship between acculturation and ethno-cultural identity.

The problems faced by the GCC countries, especially in Saudi Arabia, are different when compared to other nations. It is not easy to explain and find solutions to overcome all of them. Acculturation is a factor that can be utilized to improve a country. It is a significant area that will result in an outcome that could bridge the gap between the business and the magnanimity of a nation and its citizenship. It is highly acceptable in today's economic system worldwide, especially in the new economic order. Acculturation is as a stepping stone to the success and sustainable development of any society. The proposed research study intends to assess the acculturation process and develop strategies to utilize it for the economic development of Saudi Arabia effectively. The study aims to examine how the class people of Saudi Arabia are inclined towards acculturation and ethnocentric identity. This study also intends to build a strategy based on acculturation and ethnocultural identity and behavioral index (EIBI) of working-class people in Saudi Arabia. This research will provide useful information regarding the importance of values to understand salaried people's orientation and attitude in Saudi Arabia. Since the employee's positive attitude will be reflected in the future of the economy, with a special focus on building a strategy for socio-economic development, the findings of the study will have practical implications.

\section{Review of Literature}

\section{Definition}

Berry (1984) defined acculturation as "one in which continuous contact with a new cultural group results in psychological and behavioral changes in an individual. This process is different for all people." The meaning of acculturation emerged according to different definers' opinions in different ways and hence not specific. Different definitions over different periods show the growth of the research and scholarly thoughts on acculturation. According to Redfield et al. (1936), acculturation means if individuals are together from a different culture may change the primary culture, which is the original culture of other groups and vice versa. Portes and Zhou (1993) stated acculturation as a significant measure developed through the various school of thoughts and concluding that the change in culture arises due to association with a new culture.

\subsection{Theoretical Background}

Culture varies from one place to another, and the human behavior varies based on the emotional aspects that are socially acceptable. The lack of skilled labor and the availability of skilled people from other countries ready to migrate and settle in different other locations lead to a mix of culture. Sometimes people knowingly or unknowingly try to learn or adjust to another culture. Acculturation studies across the globe have confirmed a positive relationship between acculturation and ethnicity strategies. Yet several relationships and mediating roles which contribute towards the ethnocultural identity is still under investigation. The key factors that bring in acculturation are the expatriates who are skilled at moving or migrating from one location to another in search of a job or better living conditions. When continuous contact occurs from a particular new culture from a group of people, a psychological change occurs to the natives. The process of acculturation varies from person to person. Some will get quickly adopted to another culture by experimenting with different traditions like food, clothes, houses, and other day-to-day lifestyles. Whereas adjustment to the new culture happens (Berry 1984). Also, another dictionary definition states acculturation as assimilation towards various traditions and culture which act as the most governing one. It is the adjustment to different cultures, specifically the prevailing one. According to Nwadoria and NcAdoo (1996), the process was in adopting culture that occurs from new places, especially in the case of companies that could assimilate the migrant culture from their expatriates' employees. When a country gets mixed up with different culture results in the increased demand for goods and services. It is a potential solution to enhance the economic condition and development of major industries. It also neutralizes problems like gender inequality, social exclusion, poverty, etc. that plague most economies. Due to this, acculturation is a social requirement for an economy's well-being and is accorded as prime importance by all governments across the globe. Acculturation and enculturation are proficient enough to infuse the socio-economic development and sustainable growth of a nation. This is occurring in every segment of society.

\subsection{Ethno-cultural Identity}

The component inside the behavior of individuals emerges as a term Ethno-cultural identity, which establishes the ethnic identity, (Yamada et al., 1998). It is the focus of individuals to follow or practice a particular way of life, which may be part of their ethnicity. Ethno-cultural identity is considered a significant element in most cultures as it is part of individual identity towards their race. Several articles developed measures and constructs to identify the behavior pattern of individuals towards ethnocultural identity. Most of the time, group behavior routes to the cultural identity of specific nations or continents. One's attachment towards culture is considered as ethnic identity, and it acts as a single element of acculturation (Phinney, 1990). 


\subsection{Related Research}

The definition of acculturation is a step by step process of change in psychology in relation to culture that arises if two or more groups of different culture interact (Han, Berry \& Zheng, 2016). The change occurs in culture due to the influence of another new culture is acculturation. The culture changes are changing based on relevant modification in traditions or practices. The bidimensional acculturation model developed by Berry (1980) is based on two major concerns significant towards intercultural contact. Many studies proved that culture is the base of developing individual behavior and psychology (Kitayama, 2002). According to Fernando (2002), culture cannot remain constant or unaffected when people from different countries come to a particular country for business or job-related activities. The term cultural identity is used to commonly represent ethnic and national identity (Robinson, 2009). It was also stated that ethnic identity is highly valued by young people of the nation compared to national identity while considering other groups of people. The strategies for acculturation developed through empirical research is significantly less. Berry's Acculturation Model (Berry, 1990) is the most popular model that describes four ways: Assimilation, Integration, Separation, and Marginalization to get engaged in a culturally diversified society. According to Fishman (2001), many ethnic groups have recovered their culture and traditional language, which shows that acculturation is a process that will change continuously based on groups' requirements to generate desired outcomes. Acculturation is comparatively a neutral framework, but the concept either leads to the host country's citizens or the group migrating from another state or sometimes both. The idea of acculturation reveals the possibility of enormous opportunities for the educated, employed Saudi Arabia citizens to be involved in multicultural people working in different organizations. The people employed can easily contribute to the sustainable economic development of a nation to a greater extent. There is a shortage of literature about acculturation. Only limited studies have attempted to construct a strategic model to determine the relationship between acculturation and ethnocultural identity in Saudi Arabia. This proposed research intends to address the gap found in the review of literature.

A thorough review of the literature was done to find a suitable survey instrument for individual variables related to the research.

\section{Materials and Methods}

A descriptive research design was adopted to satisfy the research objective. The data collected through primary sources using a survey questionnaire with eighteen items adopted from Vancouver Index of Acculturation (VIA) from (Ryder et al. 1999b), after refined by Ryder et al. (2000) with two major significant subsections as Heritage and Mainstream. Two items were removed due to less score found for marriage after doing a component analysis than other factors under study. The heritage sub-score shown in the questionnaire as items with odd numbers and the mainstream sub-score shown in the even-numbered things. The scholars who want to do their research in acculturation in different contexts using mainstream need to alter accordingly to different countries based on the national target for study. Thus, the study's items were taken into consideration based on the context of expatriates migrating to Saudi Arabia and their approach towards heritage and mainstream.

Further, the questionnaire was refined based on the requirement of the title of the study. Thus, a refined and revised questionnaire was used for the present sample using the questionnaire, the required data was collected from 128 expatriates working in different sectors of Saudi Arabia. A convenient sampling method was used to collect the data. Data thus collected were thoroughly analyzed using appropriate statistical techniques like Correlation, Regression, and ANOVA.

Many studies tried to find out culture, heritage, ethnicity, etc. but there is a lack of literature towards acculturation and ethnocultural identity among expatriates in Saudi Arabia or the Middle East. This research is trying to fill the gap raised in the review of the literature. The proposed research study based on the review of literature and identified gap focus on the following objectives:

1. To study the relationship between acculturation and ethnocultural identity among the expatriates in Saudi Arabia.

2. To study the relationship between heritage and mainstream among the expatriates of Saudi Arabia.

3. To study the level of acculturation among the expatriates in Saudi Arabia

4. To suggest and examine the strategic management measures for fostering acculturation among the expatriates in Saudi Arabia

5. To give suggestions to improve socio-economic conditions using different levels of acculturation among the expatriates in Saudi Arabia

Based on these objectives, the hypotheses for the study are as stated below,

$\mathrm{H}_{1}$ : There is no significant relationship between acculturation and ethnocultural identity among the working expatriates in Saudi Arabia.

$\mathrm{H}_{2}$ : There is no significant relationship between heritage and mainstream among the working expatriates in Saudi Arabia.

$\mathrm{H}_{3}$ : There is no significant difference between age and heritage among the working expatriates in Saudi Arabia.

$\mathrm{H}_{4}$ : There is no significant difference between mainstream and age among the working expatriates in Saudi Arabia. 
$\mathrm{H}_{5}$ : There is no significant difference between marital status and heritage among the working expatriates in Saudi Arabia.

$\mathrm{H}_{6}$ : There is no significant difference between marital status and mainstream among the working expatriates in Saudi Arabia.

To measure acculturation, two major factors, Heritage and Mainstream, were used from VIA refined by Ryder et al. (2000), and this scale was tested by few other studies in a different context by Paulhus (2013) and confirmed the construct validity.

The questionnaire was converted into the context of Saudi Arabia for collecting data from expatriates, and a translated questionnaire was to understand the opinion of Saudi citizens to compare the questionnaire among different groups. Few sample questions were demonstrated as follows:

\section{PART 1 Sample items for heritage}

1. I often participate in my heritage cultural traditions.

2. I enjoy social activities with people from the same heritage culture as myself.

\section{PART 2 Sample items for Mainstream}

1. I often participate in mainstream North American cultural traditions.

2. I enjoy social activities with typical Saudi Arabian people.

The data was collected using google forms by sending them links to different groups through the mail and social media with working expatriates in different organizations. A sample of ten Saud Nationals was asked to respond in a translated questionnaire in arable language. This was used to compare the samples under study and identify the validity of the questionnaire used. Seven demographic questions were added to the questionnaire. The degree of the agreement was asked to indicate on a Five-point Likert scale by the respondents. The sample size of 128 respondents indicated their responses clearly and submitted through google forms were analyzed and tabulated to determine the results and findings of the study.

\section{Results and Discussion}

As per the statistics, 128 samples responded to the study, no missing data was found and all questions were answered.

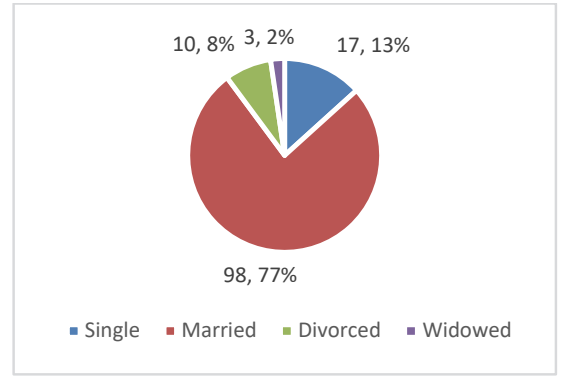

Marital status

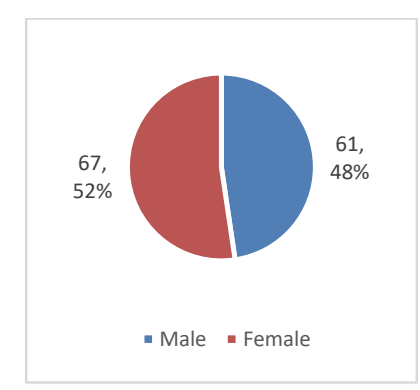

Gender

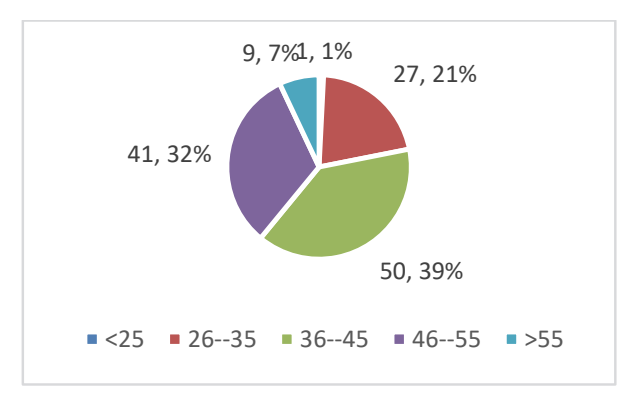

Age

Fig. 1. Respondents Demographic Profiles

Nearly Forty-eight percent of the participants were male, and fifty-two percent were females. The study focused on both male and female expatriates working in Saudi Arabia. A sample of 10 citizens of both males and females was used to identify the degree of agreement and disagreement. Thirty-nine percent of the respondents belong to the age group of 36 to 45 years old, and thirty-two percent of the respondents belong to the age group of 46 to 55 years. Twenty-one percent belong to the age group of 26 to 35 years old. Seven percent of the respondents belong to the age group above 56. Fig. 1 also shows nearly seventy-seven percent of the respondents as married, and thirty percent are single. Nearly 8 percent of the respondents were divorced, and two percent were widowed among the respondents.

\section{Table 1}

The correlation ratio between different components

\begin{tabular}{|c|c|c|c|c|}
\hline & Age & Monthly Income in Saudi Riyal & Heritage & Mainstream \\
\hline Age & 1 & & & \\
\hline Monthly Income in Saudi Riyal & .028 & 1 & & \\
\hline Heritage & $.342 * *$ & $.177^{*}$ & 1 & \\
\hline Mainstream & .081 & .095 & $.441 * *$ & 1 \\
\hline
\end{tabular}

**. Correlation is significant at the 0.01 level (2-tailed).

*. Correlation is significant at the 0.05 level (2-tailed). 
To find out the relationship between acculturation and ethnocultural identity, correlation analysis was conducted. The data collected through primary sources were analyzed using the Statistical Package for Social Science (SPSS). The analysis was conducted among two significant variables under study that is heritage and mainstream. Also, age and monthly Income from demography are used to find the correlation. Karl Pearson Correlation was conducted among the variables. A significantly low positive correlation exists among heritage and mainstream $(\mathrm{r}=.441)$, significant at 0.01 level. A very low positive correlation among age and heritage was $(\mathrm{r}=.342)$, which is significant at 0.01 level. A negligible positive correlation among monthly income and heritage $(\mathrm{r}=.177)$ is significant at 0.05 level. Hence hypothesis $\mathrm{H}_{1}$ and $\mathrm{H}_{2}$ are rejected as it is stated there is no significant correlation between Acculturation and Ethno-cultural Identity and accept the alternate hypothesis. Also, an alternate hypothesis for $\mathrm{H}_{2}$ is accepted as a positive relationship between Heritage and Mainstream was found in the correlation.

Table 2

The summary of the regression analysis

\begin{tabular}{lcccccr}
\hline & \multicolumn{2}{c}{ Unstandardized Coefficients } & \multicolumn{2}{c}{ Standardized Coefficients } & t & Sig \\
\cline { 1 - 5 } Model & $\mathrm{B}$ & Std. Error & Beta & & 4.403 & .000 \\
(Constant) & 15.850 & 3.599 & .092 & .441 & 5.513 & .000 \\
\hline Heritage & .505 & & &
\end{tabular}

a. Dependent Variable: Mainstream

$\mathrm{R}^{2}=0.194$ Adjusted $\mathrm{R}^{2}=0.188, \mathrm{~F}$-value $=30.398(0.000)$

A low positive significant relationship was found among all the variables. Further, to find which variable is more significant, a regression analysis was done. As heritage is comparatively more significant, keeping heritage as constant. The results are shown in Table 2 . The result states a 44 percent of the variation in heritage as an independent variable mainstream. $\mathrm{R}^{2}=0.194$, which is considered the contribution from heritage. To find out the significance of the variables under study, ANOVA is used by keeping mainstream as a dependent variable. The result shows the significant F statics value as 30.397 , Table 2 . Thus it is identified from the analysis that the model of regression was adequate. Heritage was kept as an independent variable and found as significant for all other variables. Thus, the null hypothesis H20 was rejected and concluded as heritage is providing a significant contribution towards Mainstream.

Table 2 shows one unit increase in heritage will lead to a 0.505 unit increase in Mainstream when all other variables are kept constant. There exists a significant positive correlation among heritage and mainstream and other variables under study. A full model regression technique was used and found as significant. Heritage is kept as an independent variable and Mainstream as a dependent variable. A part of multiple regress is indicated in the coefficient table, showing the significance level of predictors. The predicator Heritage is shown as significant (.000) with a p-value, which is less than 0.05 . Thus, the result confirms heritage as a significant variable contributing to the improvement of Mainstream with an adequate regression model.

Table 3

Group Statistics

\begin{tabular}{lllccc}
\hline & Gender & $\mathrm{N}$ & Mean & Std. Deviation & t-value \\
\hline Heritage & Male & 61 & 37.295 & 5.8319 & \\
& Female & 67 & 40.284 & 5.2909 & -3.040 \\
\hline \multirow{2}{*}{ Mainstream } & Male & 61 & 33.623 & 6.3460 & -3.165 \\
& Female & 67 & 37.179 & 6.3507 & \\
\hline
\end{tabular}

Table 3 shows group statistics in which the continuous variables were grouped into nominal variables. The group statistics include two major variables of Acculturation and ethnocultural identity, Heritage and Mainstream variables. The t-value, mean and standard deviation were carefully tabulated in Table 3. Mean value showing the male members with 37.29 and female members with 40.28 for heritage. The standard deviation for male members was 5.8 and for a female with 5.2. The mean value for a male is 33.62 , and the female is 37.17 . The standard deviation for both males and females is equal to 6.3 . To find the most significant variable t-value was found. The mean value of females in heritage is showing a high score of 40.28 . The standard deviation with a comparatively lower score for the heritage of females is equal to 5.2. This means a consistent score among females towards heritage with less spread and distributed away from the mean value. ANOVA technique is used to find the difference between demographic variables Heritage and Mainstream towards the demographic factors.

Table 4

ANOVA based on Age

\begin{tabular}{lllllll}
\hline \multirow{2}{*}{ Heritage } & Sum of Squares & df & Mean Square & F & Sig. \\
& Between group & 559.883 & 4 & 139.971 & 4.764 & 0.001 \\
& Within group & 3613.585 & 123 & 29.379 & & \\
\hline
\end{tabular}


Table 4 shows the results of ANOVA. It helps determine the difference of variables Heritage and Mainstream towards the demographic factor "Age" and found F value 4.764. Age is a significant demographic factor towards heritage. The second variable, mainstream is not having any significant difference with age. Hence rejected the null hypothesis, $\mathrm{H}_{3}$, and confirmed the alternate hypothesis that there is a significant difference between ages towards heritage. But there is no significant difference between mainstream and age among the working expatriates in Saudi Arabia and hence accept the null hypothesis $\mathrm{H}_{4}$ and reject the alternate hypothesis.

Table 4

ANOVA based on Marital status

\begin{tabular}{lllllll}
\hline & & Sum of Squares & df & Mean Square & F & Sig. \\
\hline Heritage & Between group & 27.748 & 3 & 9.249 & 0.277 & 0.842 \\
& Within group & 4145.720 & 124 & 33.433 & & \\
\hline \multirow{2}{*}{ Marital status } & Total & 4173.469 & 127 & & & \\
& Between group & 47.061 & 4 & 15.687 & 0.358 & 0.783 \\
& Within group & 5434.907 & 124 & 43.830 & & \\
\hline
\end{tabular}

Table 4 shows the ANOVA results, which is used to find the difference among variables Heritage and Mainstream towards demographic factor marital status and found $\mathrm{F}$ value 0.277 and 0.358 . It is evident from the result that there is no significant difference among demographic factor marital status towards both the variable, Heritage, and Mainstream. Hence accept the null hypothesis $\mathrm{H}_{5}$ and $\mathrm{H}_{6}$ and reject the alternate hypothesis.

\section{Conclusion}

This research study has found out that there is a relationship between acculturation and ethnocultural identity. That means heritage and mainstream is having a positive relationship. If people are conscious about their own culture, then they will readily adopt the ethnocultural identity. That means they are showing a positive affinity towards the Saudi Arabian culture. From this study, age is identified as a significant contributor to heritage, which offers a significant difference compared to other variables. This is similar to the finding of Yeh (2003). The other variable mainstream and age are not having any relationship, which shows that the expatriates are staying inside the country. Significant relationship between acculturation and ethnocultural identity is a good sign for the business and economic system. As employed expatriates who get influenced by the culture will try to buy more and more products and services locally made. This will boost the economic conditions, Dew, (2007). The expatriates in large numbers migrating from different parts of the world will mix different traditions and cultures. This will get refined once they mix with other cultures. Simultaneously, an adjustment for the food culture, dress culture, and organizational culture need to be satisfied. Expatriates are forced to buy more products or services to adjust to the climate or culture. This results in the buying of various products to satisfy their own culture and adopted culture. The circulation of money in the economy arises. Employed expatriates have more purchasing power when compared to other groups of people. Many advancements are happening in technology, and people are getting updated, yet many are not aware of adjusting to a new culture and accommodate new people to their culture. Acculturation and ethnocultural identity are a continuous process that will change society as a whole, and individuals (Balidemaj, 2016). Many alterations were needed to accommodate a new culture, whereas an old culture will remain polished. The people who were exposed to different cultures by birth or by other reasons can easily associate with varied cultural self -identities; this article also concludes that heritage and mainstream with more dimensions are better and evolving than a one dimensional. Ryder et al. (1999), is also with a similar finding in their study. A less explored area was studied in this particular research. It could fill the literature review gap.

\section{Acknowledgments}

This project was supported by Dean Scientific Research at Prince Sattam Bin Abdulaziz University under the research project number 2020/02/12145. 


\section{References}

Balidemaj, A. (2016). Acculturation, Ethnic Identity, and Psychological Well-Being of Albanian-American Immigrants in the United States, All Dissertations. 1635. https://tigerprints.clemson.edu/all_dissertations/1635

Berry, J. W. (1980). Acculturation as varieties of adaptation. In Padilla A (Ed.), Acculturation: Theory, models, and some new findings. Boulder: Westview.

Berry, J. W. (1990). Psychology of acculturation. In Cross-cultural Perspectives. Berman J (ed.). Nebraska Symposium on Motivation. Lincoln: University of Nebraska Press, 201 - 234.

Berry, J. W. (2003). Conceptual approaches to acculturation. In: Chun KM, Balls Organista P, Mar 'n G (Eds.), Acculturation: Advances in theory, measurement, and applied research. Washington, DC: American Psychological Association, $17-37$.

Berry, J.W. (1984). Multicultural policy in Canada: A social psychological analysis. Canadian Journal of Behavioural Science. 16(4), 353-370.

Dew, J.P. (2007), Two sides of the same coin? The differing roles of assets and consumer debt in marriage. Journal of Family and Economic Issues, 28, 89-104.

Fernando, S. (2002). Mental Health, Race, and Culture. Macmillan: London.

Han, L., Berry, J. W. \&, Zheng, Y. (2016). The Relationship of Acculturation Strategies to Resilience: The Moderating Impact of Social Support among Qiang Ethnicity following the 2008 Chinese Earthquake. PLoS ONE, 11(10), e0164484. DOI:10.1371/journal.pone.0164484

Kitayama, S. (2002). Culture and basic psychological processes-Toward a system view of culture: Comment on Oyserman. Psychological Bulletin, 128(1), 89-96. DOI:10.1037//0033-2909.128.1.89.

Nwadoria, E. \& McAdoo, H. (1996). Acculturation stress among Amerasian refugees: Gender and racial differences. Adolescence, 31(122), 477-87.

Paulhus, D. L. (2013). Vancouver Index of Acculturation (VIA). Measurement Instrument Database for the Social Science. Retrieved from www.midss.ie

Phinney, J. (1990), Ethnic identity in adolescence and adulthood: A review of research. Psychological Bulletin. 108, 499514.

Portes, A., \& Zhou, M. (1993). The new second generation: Segmented assimilation and its variants. The annals of the American Academy of Political and Social Science, 530(1), 74-96.

Redfield, R., Linton, R., \& Herskovits, M.J., (1936), Memorandum for the study of acculturation. American Anthropologist, $38,149-152$.

Robinson, L. (2009). Cultural identity and acculturation preferences among South Asian adolescents in Britain: An exploratory study. Children and Society, 23, 442-54.

Ryder, A. G., Alden, L. E., \& Paulhus, D. L. (1999b). Cultural identities in transition: A comparison of two acculturation models. Poster presented at the 107th Annual Convention of the American Psychological Association, Boston, MA.

Ryder, A.G., Alden, L., \& Paulhus, D.L. (2000). Is acculturation unidimensional or bidimensional?: A head-to-head comparison in the prediction of demographics, personality, self-identity, and adjustment. Journal of Personality and Social Psychology, 79, 49-65. DOI: 10.1037//0O22-3514.79.1.49

Yamada, A. M., Marsella, A. J., \& Yamada, S. Y. (1998). The development of the ethnocultural identity behavioral index: Psychometric properties and validation with Asian Americans and Pacific Islanders. Asian American and Pacific Islander Journal of Health, 6(1), 35-45.

Yeh, C. J. (2003). Age, acculturation, cultural adjustment, and mental health symptoms of Chinese, Korean, and Japanese immigrant youths. Cultural Diversity and Ethnic Minority Psychology, 9(1), 34-48. https://doi.org/10.1037/10999809.9.1.34 
(C) 2021 by the authors; licensee Growing Science, Canada. This is an open access article distributed under the terms and conditions of the Creative Commons Attribution (CC-BY) license (http://creativecommons.org/licenses/by/4.0/). 